\title{
European Journal of Orthopaedic Surgery and Traumatology
}

\section{$\underline{\text { Title Page }}$}

Title: Medical morbidities in people following hip and knee arthroplasty: data from the Osteoarthritis Initiative.

Authors: Smith TO, Penny F, Fleetcroft R

\section{Affiliations:}

Dr Toby Smith PhD - University Lecturer - School of Health Sciences, Faculty of Medicine and Health Sciences, University of East Anglia, Norwich - email: toby.smith@uea.ac.uk

Florence Penny BSc - Staff Grade Physiotherapist, Physiotherapy Department, St. Bartholomew's Hospital, London. - email: florencepenny@gmail.com

Dr Robert Fleetcroft MD - Clinical Lecturer in General Practice, Norwich Medical School, University of East Anglia, Norwich - email: R.Fleetcroft@uea.ac.uk

Corresponding Author: Dr TO Smith, Queen's Building, Faculty of Medicine and Health Sciences, University of East Anglia, Norwich Research Park, Norwich, NR4 7TJ, United Kingdom. Email: toby.smith@uea.ac.uk; Telephone: 044 (0)1603 593087; Fax: 044 (0)1603 593166

\section{Acknowledgements}

We would like to thank Professor Andy Jones, Professor in Public Health, Norwich Medical School, the University of East Anglia for reviewing this paper during its preparation.

\section{Funding}

The OAI is a public-private partnership comprised of five contracts (N01-AR-2-2258; N01-AR-22259; N01-AR-2-2260; N01-AR-2-2261; N01-AR-2-2262) funded by the National Institutes of Health, a branch of the Department of Health and Human Services, and conducted by the OAI Study Investigators. Private funding partners include Merck Research Laboratories; Novartis Pharmaceuticals Corporation, GlaxoSmithKline; and Pfizer, Inc. Private sector funding for the OAI is managed by the Foundation for the National Institutes of Health. 


\begin{abstract}
$\underline{\text { Abstract }}$
Background: Total hip (THA) and knee (TKA) arthroplasty are common orthopaedic procedures most frequently for older people. Whilst it is known that this older population frequently present with medical morbidities, no studies have previously documented the prevalence of such morbidities in people who have undergone THA or TKA. The purpose of this study was to determine the prevalence and what factors are in association with the presentation of medical morbidities in these populations.
\end{abstract}

Methods: Data from the Osteoarthritis Initiative, a population-based observational study, was assessed. In total 419 people who had undergone a THA or TKA were assessed to determine the prevalence of recorded morbidities within 12 months post-arthroplasty. All medical morbidities were then assessed using univariate and then multivariate logistic regression analysis to identify factors influencing the presentation of specific morbidities at 12 months following THA or TKA.

Results: The most common medical morbidities included: osteoporosis (16\%), mild to moderate depression $(8 \%)$, cancer $(8 \%)$, diabetes $(6 \%)$, history of stroke or TIA $(6 \%)$ and asthma $(5 \%)$. The medical morbidities demonstrated are similar between those who undergo THA and TKA. Only gender and ethnic origin were identified as statistically significant predictors of medical morbidities in these populations. Gender was a predictor of history of heart failure, whilst ethnic origin significantly predicted depression.

Conclusions: People who undergo THA or TKA may present with a variety of medical morbidities. Accordingly consideration should be made on how to encourage the adoption and maintenance of physical activity and healthy lifestyle choices for this population.

Keywords: Medical multi-morbidities; joint replacement; orthopaedic; osteoarthritis; older people 


\section{$\underline{\text { Introduction }}$}

Osteoarthritis is one of the most common musculoskeletal diseases worldwide with a prevalence of $20 \%$ to $30 \%$ [1]. It is associated with pain, stiffness, reduced independence and a reduced quality of life [2]. End-stage surgical management for osteoarthritis is arthroplasty [3]. Total hip (THA) and knee arthroplasty (TKA) are the most common forms of arthroplasty for osteoarthritis [4]. A total of 99,575 THAs and 104,378 TKAs were performed in England, Wales and Northern Ireland alone in 2014 [4].

People who undergo arthroplasty commonly present with medical morbidities [4] due to age as well as lifestyle choice, mirroring the normal population [5-7]. These morbidities can have an impact not only on people's recovery following major surgery, but also on their capabilities to engage in physical activity post-arthroplasty. A recent systematic review has identified that people following arthroplasty either return to their pre-surgical levels of physical activity, or a lower level of physical activity following THA or TKA [8]. This may be due to a number of reasons. One such reason has been attributed to pre-existing medical morbidities. Harding et al [9] in their qualitative study reported that people post-TKA adopted new reasons for not engaging in physical activity and exercise, with a recurrent 'new limitation' being cardiovascular disease and other non-communicable diseases.

Whilst it is known that this population frequently present with medical morbidities, no studies have previously documented the prevalence of such morbidities in people who have undergone THA or TKA. Furthermore, no studies have explored the existence of predictors for specific medical morbidities in this population. Such analyses would provide valuable insights to determine the overall health of this population, and whether medical morbidities should be considered when designing rehabilitation programmes following THA and TKA. Given this, the purpose of this study was to answer the following research questions: what are the most common medical morbidities in people who have recently had THA or TKA, and what factors influence the presentation of specific morbidities. 


\section{Methods}

\section{Osteoarthritis Initiative Dataset}

Data used in the preparation of this article was obtained from the Osteoarthritis Initiative (OAI) database, which is available for public access at http://www.oai.ucsf.edu/. The OAI is a large-scale, multi-centre (four sites across the USA), longitudinal cohort study aimed to investigate the role of biomarkers in the development and progression of lower limb osteoarthritis.

Baseline data collected between February 2004 and May 2006. Data has been collected longitudinally at 12, 24, 30, 36, 48, 60, 72 and 84 months post-baseline. Data collected includes individual's demographic characteristics, previous and current medical history including medical morbidities, . For this analysis, data were identified from all datasets from baseline to 84 month follow-up with the exception of Month 30 data-point since this did not present morbidity data.

\section{Cohort}

The cohort of interest was people who had undergone THA or TKA in the previous 12 months with the aim to ascertain which medical morbidities people who had undergone arthroplasty initially presented within 12 months post-operatively. The morbidities for all people who had undergone THA or TKA were included. Since this study was interested in individual's health status rather than arthroplasty per se, where people had undergone multiple arthroplasty procedures within the OAI follow-up period, we only analysed the morbidities recorded within the first 12 months of their first arthroplasty procedure to avoid multiplicity of data.

\section{Outcomes}

The outcomes of interest were self-reported medical conditions which included: osteoporosis, history of myocardial infarction, heart failure, deep vein thrombosis, liver failure, stroke or transient ischaemic attack (TIA), dementia, asthma, chronic obstructive pulmonary disease (COPD), gastric ulcer, diabetes, kidney failure, cancer (any type), psoriasis, Crohn's diseases or ulcerative colitis, rheumatoid arthritis, polymyalgia rheumatica, gout, psoriatic arthritis, ankylosing spondylitis and depression (diagnosed with the Center for Epidemiologic Studies Depression (CES-D) scale) with the thresholds: less than 15 no depression; 15-21 mild to moderate depression; over 21 possibility of major depression [10]. In addition to these individual conditions, data on the Charlson Comorbidity Index, a valid and reliable tool used to predict mortality by classifying 19 comorbidities [11], was also collected.

\section{Data analysis}

The prevalence of each medical morbidity was determined with $95 \%$ confidence intervals (CI). All medical morbidities were then assessed using univariate logistic regression analysis to identify factors influencing their presentation. The dependent variables were the presence of the following self-reported morbidities: osteoporosis, history of myocardial infarct, heart failure, deep vein thrombosis, liver failure, stroke or TIA, dementia, asthma, COPD, gastric ulcer, diabetes, kidney failure, cancer (any), psoriasis, Crohn's diseases or 
ulcerative colitis, rheumatoid arthritis, polymyalgia rheumatica, gout, psoriatic arthritis, ankylosing spondylitis and depression. Independent variables identified through previous research as potential explanatory factors included: age at arthroplasty, gender, ethnic origin, height and weight and arthroplasty procedure (THA or TKA). Based on these, all variables identified as significant at $\mathrm{p}<0.1$ on univariate analysis were entered into a multivariate logistical regression model. All logistical regression data was expressed as odd ratios (OR) with 95\% CI and p-values. The Wald statistic was used to assess statistical significance in each regression model. All analyses were undertaken using STATA version 12.0 (STATACorp LP, Texas, USA).

\section{Ethics approval}

Committee on Human Research, University of California, San Francisco (IRB approval number 10-00532 Approved 10 $0^{\text {th }}$ March 2015). 


\section{$\underline{\text { Results }}$}

Figure 1 illustrates the subject selection based on the a priori eligibility criteria. In total, 419 individuals were included in the analysis (110 THA/309 TKA). The demographic characteristics of the cohort are presented in Table 1. Mean age was 69.3 years (67.7 THA/69.9 TKA). The cohort consisted of 172 males and 247 females. In the THA cohort, gender composition was 50 males and 60 females. In the TKA cohort this was 122 males and 187 females. The most predominant ethnic group were Caucasians (81.4\% of the total cohort). Mean maximum adult weight reported was $88.4 \mathrm{~kg}(87.8 \mathrm{~kg}$ THA $/ 88.6 \mathrm{~kg}$ TKA). Mean minimum adult weight reported was $62.3 \mathrm{~kg}(63.8 \mathrm{~kg}$ THA/61.7 kg TKA).

\section{Prevalence of morbidities}

A summary of the prevalence values and confidence intervals for each of the reported medical morbidity is presented in Table 2. The most prevalent medical morbidity was osteoporosis (15.5\%; $10.0 \%$ THA/17.5\% TKA). After this, the most common morbidities were mild to moderate depression $(8.4 \% ; 10.0 \%$ THA/7.8\% TKA), a history of cancer (any type; $8.1 \%$ total; 8.1\% THA/8.1\% TKA), diabetes (5.7\%; 6.4\% THA/5.5\% TKA) and a history of stroke or TIA (5.5\%; $4.8 \%$ THA $/ 5.7 \%$ TKA). The prevalence for cardiac and respiratory morbidities was lower for a history of myocardial infarct (3.7\% total; $6.5 \%$ THA/2.9\% TKA), a history of heart failure (3.0\% total: $0.0 \%$ THA; $3.8 \%$ TKA), asthma (4.8\% total; $4.6 \%$ THA/4.9\% TKA), and COPD (3.0\% total; $4.8 \%$ THA/2.4\% TKA).

There was a low prevalence for morbidities such as dementia (0.0\% total and THA/TKA), Crohn's disease or ulcerative colitis $(0.1 \%$; $0.9 \%$ THA/ $0.0 \%$ TKA), psoriatic arthritis $(0.1 \% ; 0.0 \%$ THA; $0.3 \%$ TKA), polymyalgia rheumatic $(0.5 \% ; 0.0 \%$ THA/0.7\% TKA) and ankylosing spondylitis $(0.6 \% ; 1.8 \%$ THA/0.3\% TKA).

Mean Charlson Co-morbidity Index was 0.57 (standard deviation (SD): 0.97) for the total cohort, 0.56 (SD: 0.93 ) for THA and 0.57 (SD: 0.98) for TKA. Forty-three people (10.3\%) presented with two or more morbidities in the total cohort (THA: $n=10(9 \%)$; TKA: $n=33(10.7 \%)$ ).

\section{Predictors of medical morbidities}

Table 3 presents the results of the logistical regression analysis. As this demonstrates, there were significant predictors for nine morbidities (history of myocardial infarct; history of heart failure; asthma; diabetes; history of kidney failure; history of cancer (any type); rheumatoid arthritis; gout; depression). The most frequently identified predictor characteristic was maximum adult weight. This was a significant predictor for: a history of heart failure (OR: 1.04; 95\% CI: 1.00-1.09), history of kidney failure (OR: 1.07; 95\% CI: 1.02-1.13), history of cancer (any type) (OR: 1.03; 95\% CI: 1.01-1.06) and rheumatoid arthritis (OR: 0.97; 95\% CI: 0.93-1.00). With the exception of rheumatoid arthritis, the higher the maximum adult weight, the greater likelihood of experiencing these morbidities. Conversely, minimum adult weight was a significant predictor for asthma (OR: 0.95; 95\% CI: 0.90-1.00), history of cancer (any type) (OR: 1.04; 95\% CI: 1.01-1.08) and gout (OR: 1.05; 95\% 
CI: 0.99-1.10). With the exception of asthma, the higher the minimum adult weight, the greater the likelihood of experiencing these morbidities. Mean weight at 25 years of age was a significant predictor of history of cancer (any type) (OR: 1.04; 95\% CI: 1.01-1.07) and gout (OR: 1.05; 95\% CI: 1.00-1.05). Higher weight equated to greater the likelihood of experiencing these morbidities. Mean height at 25 years of age was associated with a history of heart failure (OR: 1.01; 95\% CI: 1.00-1.02) with greater height associated with greater likelihood of experiencing this morbidity.

Gender was identified as a significant predictor for a history of myocardial infarct (OR: 6.24; 95\% CI: 1.30 29.95), a history of heart failure (OR: 4.59; 95\% CI: 0.91-23.16) and a history of cancer (any type) (OR: 2.26; 95\% CI: 0.93-5.50), where males were more likely to experience these morbidities. Ethnic origin was identified as a significant predictor for diabetes (OR: 2.11; 95\% CI: 0.95-4.65). However, when analysed individually, none of the categories of race were identified as specific predictors. Age at arthroplasty was only a predictor for depression (based on CES-D thresholds (OR: 0.97; 95\% CI: 0.94-1.01); where lower age was associated with a greater likelihood of depression. The type of joint replacement received i.e. THA or TKA, was not identified as a predictor in this dataset.

The findings of the multivariate logistical regression model are presented in Supplementary Table 1. This indicated that only gender, ethnic origin and mean weight at aged 25 years were significant predictors of morbidities. The model indicated that males were 0.21 times at lower likelihood of having a history of heart failure compared to females (OR: 0.21; 95\% CI: 0.94-23.95). Ethnic origin was a significant predictor overall for experiencing depression (OR: 3.58; 95\% CI: 1.92-6.66). However when assessed by categorising individual ethnic groups, there was no statistically significant difference in predictive values between Caucasian, AfricanAmerican or Asian groups ( $\mathrm{p}=0.99$ ). Finally mean weight at aged 25 was a statistically significant predictor of gout, where an increase of one kilogram was associated with an increased likelihood of experiencing gout by 0.1 times (OR: 1.05; 95\% CI: 1.00-1.10). 


\section{Discussion}

The findings of this study indicate that people who undergo THA or TKA present with a number of important morbidities. The morbidities demonstrated were similar between those who underwent a THA or TKA. The most common morbidities included: osteoporosis, mild to moderate depression, cancer, diabetes, history of stroke or TIA and asthma. Medical morbidities which least frequently present in this population include dementia, Crohn's disease, polymyalgia and psoriatic arthritis. Only gender and ethnic origin were identified as statistically significant predictors of morbidities, with gender a predictor of history of heart failure, whilst ethnic origin significantly predicted depression.

This study is the first paper to identify what specific morbidities people following THA and TKA present with. The results suggest that the most common medical co-morbidities are non-communicable diseases. Morbidities such as osteoporosis, depression, cancer, diabetes, and stroke/TIA are all diseases frequently seen within this age group in the normative population and non-arthroplasty cohorts [5-7], where mean age for a hip and knee arthroplasty is 70 years [4]. This paper is therefore valuable as it provides an insight into possible morbidities which may influence rehabilitation and recovery [12]. These diseases could have a detrimental effect on postoperative outcome, potentially increasing risks of complications such as wound infections and reduced exercise capability, both in the short- and longer-term post-THA and TKA $[13,14]$. This should be considered when designing generic rehabilitation pathways, accounting for these possible conditions, providing the flexibility to adapt progression based on these morbidities' physiological impact.

A secondary value of this analysis was that we have identified potential predictors for these morbidities in this population. On univariate analysis, weight at age 25 years and maximum weight were identified as recurrent significant predictors. Whilst these were not supported on multivariate analysis, previous studies have also identified the importance of these factors [15]. It is widely recognised that weight management programmes are an important component for the non-surgical management of hip and knee osteoarthritis [16]. This data would therefore further support this, providing added rationale for the potential benefit that weight management for this post-arthroplasty cohort, could have on reducing the associated risks with these morbidities.

The type of arthroplasty undergone (THA or TKA) was not a significant predictor of morbidity. This suggests homogeneity in the co-existing medical conditions experienced by these populations. Thus, when generic rehabilitation programmes are designed and delivered following THA and TKA, consideration on the underlying morbidities this population present should not be a distinguishing factor between regimes. Consequently, the rehabilitation needs for this population in terms of muscle strength, loss of range of motion, gait re-education and improving balance and functional performance [17] should be the primary concern for each cohort.

Previous research has identified that a patients' physical activity either maintains at a pre-surgical levels or reduces following THA or TKA. The burden on individuals in this study, their families and health services, of the most commonly identified morbidities can be reduced through the adoption of physical activity and lifestyle programmes. Previous research has provided a rigorous evidence-base in support of the adoption of physical activity strategies in the management of osteoporosis [18], depression [19], diabetes [20] and asthma [21]. However encouraging and maintaining physical activity programmes in this population has been highlighted as 
challenging, particularly for long term-adherence [8]. Given the encouragement to adopt a 'making-everycontact-count' approach to health promotion [22], clinicians such as orthopaedic surgeons, physiotherapists, occupational therapists, community nurses and general practitioners could have a significant role in highlighting the threat of these morbidities within routine follow-up consultations post-arthroplasty. Further research is warranted on strategies to target such morbidities to improve both the physical and mental health of this population, given the potential beneficial impact these could have on long-term primary and secondary care management.

This study presented with three limitations. The data of medical morbidities derived from the OAI dataset was self-reported. Consequently, the morbidities reported may have been influenced by systematic errors through individual's capability to recall medical history. Secondly the OAI dataset identified morbidities which where $a$ priori defined as important. Therefore these individuals may have presented with other morbidities which were not assessed as part of the data collection process. Nonetheless, the morbidities recorded are those most frequently reported in previous non-arthroplasty cohorts with comparable age and sex-matched characteristics [5-7]. Also the Charlson Co-morbidity Index was low (total cohort mean: 0.57) suggesting that the reported morbidities were potentially attributable to the morbidities reported. Finally, the OAI database is a cohort of individuals from North America. Whilst this providers valuable data, there may be limited generalisability to other continents such as Asia, Africa and Europe. Further validation work may, therefore, be warranted to ascertain how these findings relate to other nationalities before considering the translation of these results into public health strategies.

\section{Conflicts of Interest}

Competing interests: The authors declare that they have no conflict of interest.

Funding: The OAI is a public-private partnership comprised of five contracts (N01-AR-2-2258; N01-AR-22259; N01-AR-2-2260; N01-AR-2-2261; N01-AR-2-2262) funded by the National Institutes of Health, a branch of the Department of Health and Human Services, and conducted by the OAI Study Investigators. Private funding partners include Merck Research Laboratories; Novartis Pharmaceuticals Corporation, GlaxoSmithKline; and Pfizer, Inc. Private sector funding for the OAI is managed by the Foundation for the National Institutes of Health.

Informed consent: Informed consent was obtained from all individual participants included in the study.

Ethics approval: Committee on Human Research, University of California, San Francisco (IRB approval number 10-00532 Approved 10 $0^{\text {th }}$ March 2015).

Data sharing statement: This manuscript was prepared using an OAI public use data set and does not necessarily reflect the opinions or views of the OAI investigators, the NIH, or the private funding partners. 


\section{Figure and Table Legends}

Figure 1: Flow-chart illustrating the subject selection based on a priori eligibility criteria.

Table 1: Demographic characteristics

Table 2: Frequency of morbidities (overall and by arthroplasty)

Table 3: Result of the univariate logistical regression analysis (OR, 95\% confidence interval; $p$-values) for predicting specific morbidities.

Supplementary Table 1. Multivariate logistic regression analysis (OR, 95\% confidence interval; $p$-values for predictors and $\mathrm{p}$-values for non-predictors) for predicting specific morbidities identified as significant on univariate analysis. 


\section{$\underline{\text { References }}$}

1. Arden N, Nevitt MC (2006) Osteoarthritis: epidemiology. Best Pract Res Clin Rheumatol 20:3-25.

2. Woolf A, Pfleger B (2003) Burden of major musculoskeletal conditions. Bull World Health Organ $81: 646-656$.

3. NICE. Osteoarthritis - Quality standard 87. June 2015. Available at:

https://www.nice.org.uk/guidance/qs87/resources/guidance-osteoarthritis-pdf Accessed: 15.06.2015.

4. National Joint Registry. Stats Online. Available at:

http://www.njrcentre.org.uk/njrcentre/Healthcareproviders/Accessingthedata/StatsOnline/tabid/117/Default.aspx Accessed on 01.12.2014.

5. Reyes C, Estrada P, Nogués X, Orozco P, Cooper C, Díez-Pérez A, Formiga F, Mácias JG, PrietoAlhambra D (2014) The impact of common co-morbidities (as measured using the Charlson index) on hip fracture risk in elderly men: a population-based cohort study. Osteoporos Int 25:1751-1758.

6. Caughey GE, Roughead EE, Shakib S, Vitry AI, Gilbert AL (2011) Co-morbidity and potential treatment conflicts in elderly heart failure patients: a retrospective, cross-sectional study of administrative claims data. Drugs Aging 28:575-581.

7. Tan CP, Ng A, Civil I (2004) Co-morbidities in trauma patients: common and significant. N Z Med J 117:U1044.

8. Smith TO, Latham SK, Maskrey V, Blyth A (2015) What are people's perceptions of physical activity before and after joint replacement? A systematic review and meta-ethnography. Postgrad Med J: In Press.

9. Harding PA, Holland AE, Hinman RS, Delany C (2015) Physical activity perceptions and beliefs following total hip and knee arthroplasty: a qualitative study. Physiother Theory Pract 31:107-113.

10. Radloff LS (1977) The CES-D scale: A self report depression scale for research in the general population. Appl Psychol Measure 1:385-401.

11. Charlson ME, Pompei P, Ales KL, MacKenzie CR (1987) A new method of classifying prognostic comorbidity in longitudinal studies: development and validation. J Chronic Dis 40:373-383.

12. Hoang-Kim A, Busse JW, Groll D, Karanicolas PJ, Schemitsch E (2014) Co-morbidities in elderly patients with hip fracture: recommendations of the ISFR-IOF hip fracture outcomes working group. Arch Orthop Trauma Surg 134:189-195.

13. de Thomasson E, Caux I, Guingand O, Terracher R, Mazel C (2009) Total hip arthroplasty for osteoarthritis in patients aged 80 years or older: influence of co-morbidities on final outcome. Orthop Traumatol Surg Res 95:249-253.

14. Niki Y, Katsuyama E, Takeda Y, Enomoto H, Toyama Y, Suda Y (2014) Comparison of postoperative morbidity between simultaneous bilateral and staged bilateral total knee arthroplasties: serological perspective and clinical consequences. J Arthroplasty 29:504-509.

15. Booth HP, Prevost AT, Gulliford MC (2015) Severity of obesity and management of hypertension, hypercholesterolaemia and smoking in primary care: population-based cohort study. J Hum Hypertens: In Press.

16. Peeler J, Christian M, Cooper J, Leiter J, MacDonald P (2015) Managing knee osteoarthritis: the effects of body weight supported physical activity on joint pain, function, and thigh muscle strength. Clin $\mathbf{J}$ Sport Med: In Press.

17. Saufl N, Owens A, Kelly I, Merrill B, Freyaldenhouen LL (2007) A multidisciplinary approach to total joint replacement. J Perianesth Nurs 22:195-206. 
18. Heidari B, Hosseini R, Javadian Y, Bijani A, Sateri MH, Nouroddini HG (2015) Factors affecting bone mineral density in postmenopausal women. Arch Osteoporos 10:217.

19. Black SV, Cooper R, Martin KR, Brage S, Kuh D, Stafford M (2015) Physical activity and mental well-being in a cohort aged 60-64 years. Am J Prev Med: In Press.

20. Hamasaki H, Noda M, Moriyama S, Yoshikawa R, Katsuyama H, Sako A, Mishima S, Kakei M, Ezaki O, Yanai H (2015) Daily physical activity assessed by a triaxial accelerometer is beneficially associated with waist circumference, serum triglycerides, and insulin resistance in Japanese patients with prediabetes or untreated early type 2 diabetes. J Diabetes Res: In Press.

21. Ma J, Strub P, Xiao L, Lavori PW, Camargo CA Jr, Wilson SR, Gardner CD, Buist AS, Haskell WL, Lv N (2015) Behavioral weight loss and physical activity intervention in obese adults with asthma. A randomized trial. Ann Am Thorac Soc 12:1-11.

22. Spring B, Moller AC, Colangelo LA, Siddique J, Roehrig M, Daviglus ML, Polak JF, Reis JP, Sidney S, Liu K (2014) Healthy lifestyle change and subclinical atherosclerosis in young adults: Coronary Artery Risk Development in Young Adults (CARDIA) study. Circulation 130:10-17. 
Figure 1: Flow-chart illustrating the subject selection based on a priori eligibility criteria.

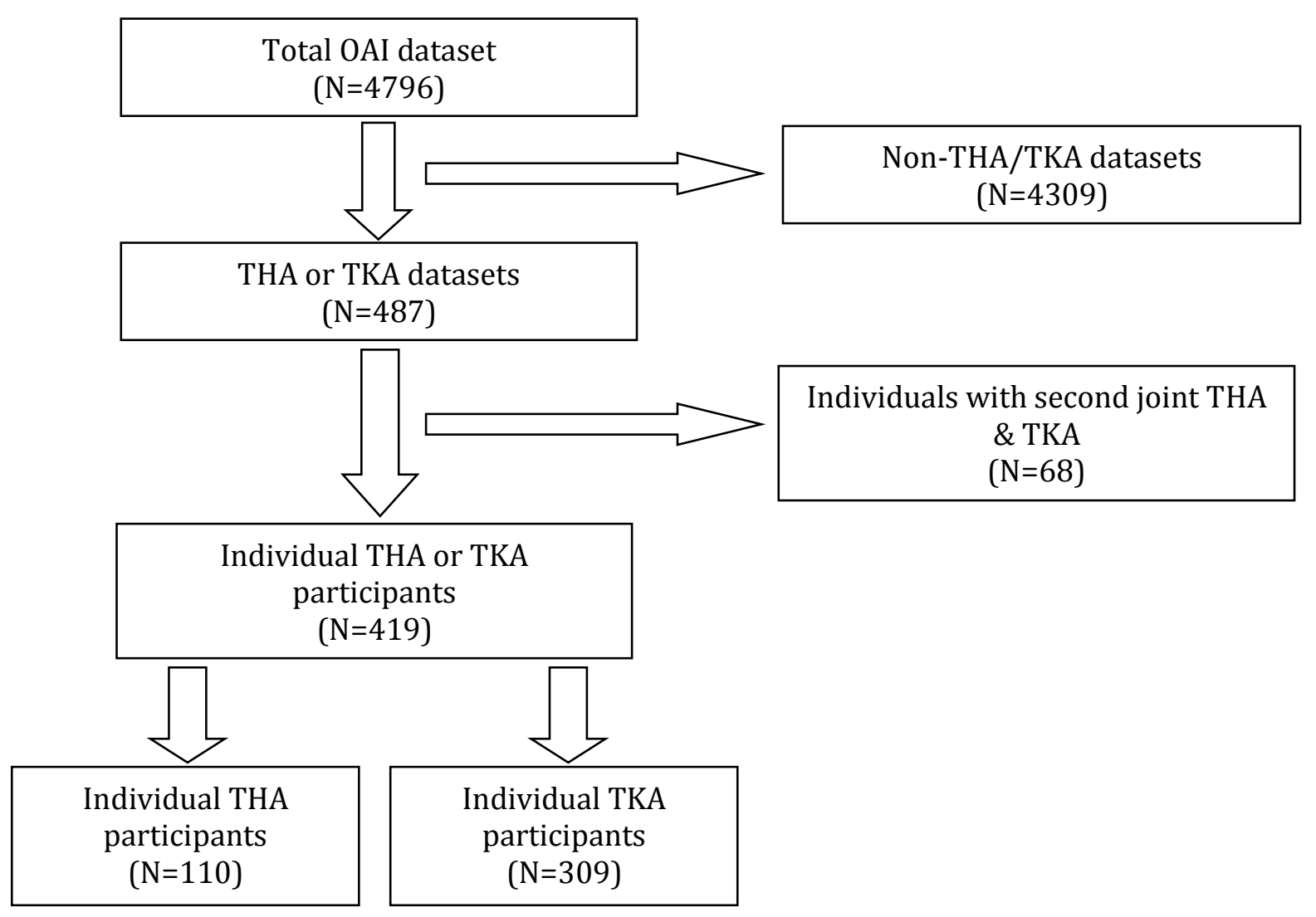


Table 1: Demographic characteristics

\begin{tabular}{l|c|c|c}
\hline & Total Cohort & THA & TKA \\
\hline $\mathrm{N}$ & 419 & 110 & 309 \\
\hline Mean age at arthroplasty in years (SD) & $69.3(26.9)$ & $67.7(9.4)$ & $69.9(31.0)$ \\
\hline Gender (m/f) & $172 / 247$ & $50 / 60$ & $122 / 187$ \\
\hline Race & & & 0 \\
\hline$\quad$ Non-white & 8 & 2 & 248 \\
\hline$\quad$ Caucasian & 341 & 93 & 52 \\
\hline$\quad$ African-American & 66 & 14 & 3 \\
\hline$\quad$ Asian & 4 & 1 & $1.65(0.25)$ \\
\hline Mean height at aged 25 in meters (SD) & $1.65(0.26)$ & $1.65(0.29)$ & $67.3(13.0)$ \\
\hline Maximum adult weight in kg (SD) & $67.8(13.0)$ & $69.1(13.2)$ & $88.6(16.9)$ \\
\hline Minimum adult weight in kg (SD) & $88.4(16.2)$ & $87.8(14.4)$ & $61.7(11.3)$ \\
\hline
\end{tabular}

F - female; kg- kilograms; M - Males; N - number; SD - standard deviation; THA - total hip arthroplasty; TKR - total knee arthroplasty 
Table 2: Frequency of morbidities (overall and by arthroplasty)

\begin{tabular}{|c|c|c|c|c|c|c|}
\hline \multirow[t]{2}{*}{ Frequency of morbidities } & \multicolumn{2}{|c|}{ Total Cohort $(\mathrm{N}=419)$} & \multicolumn{2}{|c|}{ THA (N=110) } & \multicolumn{2}{|c|}{ TKA $(\mathrm{N}=309)$} \\
\hline & Frequency & $\begin{array}{c}\text { Prevalence (\%) } \\
(95 \% \text { CI })\end{array}$ & Frequency & $\begin{array}{c}\text { Prevalence (\%) } \\
(95 \% \text { CI })\end{array}$ & Frequency & $\begin{array}{l}\text { Prevalence }(\%) \\
(95 \% \text { CI })\end{array}$ \\
\hline Osteoporosis & $65 / 419$ & $15.5(12.4-19.3)$ & $11 / 110$ & $10.0(5.7-17.0)$ & $54 / 309$ & $17.5(13.7-22.1)$ \\
\hline History of myocardial infarct & $10 / 271$ & $3.7(2.0-6.7)$ & $4 / 62$ & $6.5(2.5-15.5)$ & $6 / 209$ & $2.9(1.3-6.1)$ \\
\hline History of heart failure & $8 / 271$ & $3.0(1.5-5.7)$ & $0 / 62$ & $0.0(0.0-0.0)$ & $8 / 209$ & $3.8(2.0-7.4)$ \\
\hline History of deep vein thrombosis or PE & $4 / 274$ & $1.5(0.6-3.7)$ & $0 / 62$ & $0.0(0.0-0.0)$ & $4 / 209$ & $1.9(0.7-4.8)$ \\
\hline History of liver failure & $4 / 271$ & $1.5(0.6-3.7)$ & $0 / 62$ & $0.0(0.0-0.0)$ & $4 / 209$ & $1.9(0.7-4.8)$ \\
\hline History of Stroke or TIA & $15 / 271$ & $5.5(3.4-8.9)$ & $3 / 62$ & $4.8(1.7-13.3)$ & $12 / 209$ & $5.7(3.3-9.8)$ \\
\hline Dementia & $0 / 419$ & $0.0(0.0-0.0)$ & $0 / 110$ & $0.0(0.0-0.0)$ & $0 / 309$ & $0.0(0.0-0.0)$ \\
\hline Asthma & $20 / 419$ & $4.8(3.1-7.3)$ & $5 / 110$ & $4.6(2.0-10.2)$ & $15 / 309$ & $4.9(3.0-7.9)$ \\
\hline COPD & $8 / 271$ & $3.0(1.5-5.7)$ & $3 / 62$ & $4.8(1.7-13.3)$ & $5 / 209$ & $2.4(0.1-5.5)$ \\
\hline Diabetes & $24 / 419$ & $5.7(3.9-8.4)$ & $7 / 110$ & $6.4(3.1-12.6)$ & $17 / 309$ & $5.5(3.5-8.6)$ \\
\hline History of kidney failure & $7 / 271$ & $2.6(1.3-5.2)$ & $2 / 62$ & $3.2(0.9-11.0)$ & $5 / 209$ & $2.4(1.0-5.5)$ \\
\hline History of cancer (any) & $22 / 271$ & $8.1(5.4-12.0)$ & $5 / 62$ & $8.1(3.5-17.5)$ & $17 / 209$ & $8.1(5.1-12.6)$ \\
\hline Psoriasis & $11 / 419$ & $2.6(1.5-4.7)$ & $1 / 110$ & $0.9(0.2-5.0)$ & $10 / 309$ & $3.2(1.8-5.9)$ \\
\hline History of Crohn's diseases or ulcerative colitis & $1 / 419$ & $0.1(0.0-1.1)$ & $1 / 110$ & $0.9(0.2-5.0)$ & $0 / 309$ & $0.0(0.0-0.0)$ \\
\hline Rheumatoid arthritis & $12 / 419$ & $2.9(1.6-4.9)$ & $1 / 110$ & $0.9(0.2-5.0)$ & $11 / 309$ & $3.6(2.0-6.3)$ \\
\hline Polymyalgia rheumatica & $2 / 419$ & $0.5(0.1-1.7)$ & $0 / 110$ & $0.0(0.0-0.0)$ & $2 / 309$ & $0.7(0.2-2.3)$ \\
\hline Gout & $9 / 419$ & $2.8(1.1-4.0)$ & $2 / 110$ & $1.8(0.5-6.4)$ & $7 / 309$ & $2.3(1.1-4.6)$ \\
\hline Psoriatic arthritis & $1 / 419$ & $0.1(0.0-1.1)$ & $0 / 110$ & $0.0(0.0-0.0)$ & $1 / 309$ & $0.3(0.1-0.2)$ \\
\hline Ankylosing spondylitis & $3 / 419$ & $0.6(0.0-2.1)$ & $2 / 110$ & $1.8(0.5-6.4)$ & $1 / 309$ & $0.3(0.1-0.2)$ \\
\hline \multicolumn{7}{|l|}{ Depression (based on CES-D thresholds) } \\
\hline No depression & $368 / 419$ & $87.8(84.4-90.6)$ & $94 / 110$ & $85.5(77.7-90.8)$ & $274 / 309$ & $88.7(84.7-91.7)$ \\
\hline Mild to moderate depression & $35 / 419$ & $8.4(6.1-11.4)$ & $11 / 110$ & $10.0(5.7-17.0)$ & $24 / 309$ & $7.8(5.3-11.3)$ \\
\hline Possible major depression & $15 / 419$ & $3.6(2.2-5.8)$ & $4 / 110$ & $3.6(1.4-9.0)$ & $11 / 309$ & $3.6(2.0-6.3)$ \\
\hline Mean CES-D score (SD) & $6.94(6.68)$ & $\mathrm{N} / \mathrm{E}$ & $7.64(8.01)$ & $\mathrm{N} / \mathrm{E}$ & $6.72(6.13)$ & $\mathrm{N} / \mathrm{E}$ \\
\hline Mean Charlson Comorbidity Index (SD) & $0.57(0.97)$ & $\mathrm{N} / \mathrm{E}$ & $0.56(0.93)$ & $\mathrm{N} / \mathrm{E}$ & $0.57(0.98)$ & $\mathrm{N} / \mathrm{E}$ \\
\hline
\end{tabular}

Mean Charlson Comorbidity Index (SD)

$0.57(0.97) \quad$ N/E

$\mathrm{N} / \mathrm{E}$

$0.57(0.98)$

$\mathrm{N} / \mathrm{E}$

CES-D - Center for Epidemiologic Studies Depression; CI - confidence interval; COPD - chronic obstructive pulmonary disease; N/E - not estimable; PE - pulmonary embolism; SD - standard deviation; THA - total hip arthroplasty; TIA - transient ischaemic attack; TKA - total knee arthroplasty. 
Table 3: Result of the univariate logistical regression analysis (OR, 95\% confidence interval; $p$-values) for predicting specific morbidities.

\begin{tabular}{|c|c|c|c|c|c|c|c|c|}
\hline & $\begin{array}{l}\text { Mean age at } \\
\text { arthroplasty }\end{array}$ & $\begin{array}{l}\text { Gender } \\
\text { (male:female) }\end{array}$ & Ethnic origin & $\begin{array}{l}\text { Mean height } \\
\text { at aged } 25\end{array}$ & $\begin{array}{l}\text { Mean weight } \\
\text { at aged } 25\end{array}$ & $\begin{array}{l}\text { Maximum } \\
\text { adult weight }\end{array}$ & $\begin{array}{l}\text { Minimum } \\
\text { adult weight }\end{array}$ & $\begin{array}{l}\text { Type of } \\
\text { Arthroplasty }\end{array}$ \\
\hline Osteoporosis & $\begin{array}{l}0.98(0.94- \\
1.01 ; 0.19)\end{array}$ & $\begin{array}{l}1.18(0.66-2.11 ; \\
0.57)\end{array}$ & $\begin{array}{l}0.31(0.05- \\
1.93 ; 0.21) \\
\end{array}$ & $\begin{array}{l}1.00(1.00- \\
1.00 ; 0.59)\end{array}$ & $\begin{array}{l}1.00(0.05- \\
3.49 ; 0.88) \\
\end{array}$ & $\begin{array}{l}0.99(0.94- \\
1.01 ; 0.32) \\
\end{array}$ & $\begin{array}{l}0.99(0.97- \\
1.00 ; 0.22)\end{array}$ & $\begin{array}{l}0.84(0.46- \\
1.58 ; 0.60) \\
\end{array}$ \\
\hline History of myocardial infarct & $\begin{array}{l}0.95(0.84- \\
1.07 ; 0.42) \\
\end{array}$ & $\begin{array}{l}6.24(1.30- \\
29.95 ; 0.02)\end{array}$ & $\begin{array}{l}0.31(0.04- \\
2.37 ; 0.26) \\
\end{array}$ & $\begin{array}{l}1.00(0.99- \\
1.01 ; 0.86) \\
\end{array}$ & $\begin{array}{l}1.00(0.00- \\
0.00 ; 1.00) \\
\end{array}$ & $\begin{array}{l}1.03(0.99- \\
1.08 ; 0.19) \\
\end{array}$ & $\begin{array}{l}1.02(0.98- \\
1.06 ; 0.30) \\
\end{array}$ & $\begin{array}{l}0.43(0.12- \\
1.57 ; 0.20) \\
\end{array}$ \\
\hline History of heart failure & $\begin{array}{l}0.99(0.87- \\
1.11 ; 0.80)\end{array}$ & $\begin{array}{l}4.59(0.91- \\
23.16 ; 0.07)\end{array}$ & $\begin{array}{l}1.44(0.20- \\
10.27 ; 0.72)\end{array}$ & $\begin{array}{l}1.01(1.00- \\
1.02 ; 0.08)\end{array}$ & $\begin{array}{l}1.03(0.99- \\
1.09 ; 0.17)\end{array}$ & $\begin{array}{l}1.04(1.00- \\
1.09 ; 0.09)\end{array}$ & $\begin{array}{l}1.05(0.99- \\
1.10 ; 0.12)\end{array}$ & $\begin{array}{l}0.00(0.00- \\
0.00 ; 1.00)\end{array}$ \\
\hline $\begin{array}{l}\text { History of deep vein thrombosis } \\
\text { or PE }\end{array}$ & $\begin{array}{l}1.00(0.98- \\
1.03 ; 0.87)\end{array}$ & $\begin{array}{l}1.47(0.20- \\
10.61 ; 0.70)\end{array}$ & $\begin{array}{l}1.44(0.20- \\
10.27 ; 0.72)\end{array}$ & $\begin{array}{l}1.00(0.99- \\
1.01 ; 0.59)\end{array}$ & $\begin{array}{l}1.01(0.94- \\
1.08 ; 0.87)\end{array}$ & $\begin{array}{l}1.02(0.96- \\
1.08 ; 0.61)\end{array}$ & $\begin{array}{l}1.01(0.93- \\
1.09 ; 0.86)\end{array}$ & $\begin{array}{l}0.00(0.00- \\
0.00 ; 1.00)\end{array}$ \\
\hline History of liver failure & $\begin{array}{l}0.92(0.78- \\
1.10 ; 0.37) \\
\end{array}$ & $\begin{array}{l}0.48(0.05-4.71 \\
0.53)\end{array}$ & $\begin{array}{l}1.17(0.38- \\
3.55 ; 0.79)\end{array}$ & $\begin{array}{l}1.00(0.98- \\
1.01 ; 0.30)\end{array}$ & $\begin{array}{l}0.93(0.84- \\
1.04 ; 0.23)\end{array}$ & $\begin{array}{l}0.98(0.92- \\
1.04 ; 0.53)\end{array}$ & $\begin{array}{l}0.93(0.82- \\
1.04 ; 0.21)\end{array}$ & $\begin{array}{l}0.00(0.00- \\
0.00 ; 1.00)\end{array}$ \\
\hline History of Stroke or TIA & $\begin{array}{l}1.00(0.98- \\
1.02 ; 0.99)\end{array}$ & $\begin{array}{l}1.30(0.46-3.70 \\
0.62)\end{array}$ & $\begin{array}{l}1.17(0.39- \\
3.55 ; 0.79)\end{array}$ & $\begin{array}{l}1.00(1.00- \\
1.00 ; 0.96)\end{array}$ & $\begin{array}{l}1.00(0.96- \\
1.04 ; 0.97)\end{array}$ & $\begin{array}{l}1.01(0.97- \\
1.04 ; 0.71)\end{array}$ & $\begin{array}{l}1.00(0.96- \\
1.05 ; 0.94)\end{array}$ & $\begin{array}{l}0.84(0.23- \\
3.06 ; 0.79)\end{array}$ \\
\hline Dementia & $\begin{array}{l}0.99(0.97- \\
1.01 ; 0.45)\end{array}$ & $\begin{array}{l}0.87(0.58-1.31 \\
0.51)\end{array}$ & $\begin{array}{l}0.93(0.59- \\
1.48 ; 0.77) \\
\end{array}$ & $\begin{array}{l}1.00(1.00- \\
1.00 ; 0.70)\end{array}$ & $\begin{array}{l}1.00(1.00- \\
1.02 ; 0.58)\end{array}$ & $\begin{array}{l}1.00(0.99- \\
1.01 ; 0.67)\end{array}$ & $\begin{array}{l}1.00(0.99- \\
1.02 ; 0.77)\end{array}$ & $\begin{array}{l}1.09(0.69- \\
1.70 ; 0.72)\end{array}$ \\
\hline Asthma & $\begin{array}{l}0.98(0.92- \\
1.03 ; 0.42)\end{array}$ & $\begin{array}{l}0.61(0.23-1.63 ; \\
0.32)\end{array}$ & $\begin{array}{l}1.48(0.59- \\
3.70 ; 0.41)\end{array}$ & $\begin{array}{l}1.00(0.99- \\
1.00 ; 0.25)\end{array}$ & $\begin{array}{l}0.97(0.93- \\
1.01 ; 0.13)\end{array}$ & $\begin{array}{l}1.00(0.98- \\
1.03 ; 0.83)\end{array}$ & $\begin{array}{l}0.95(0.90- \\
1.00 ; 0.03)\end{array}$ & $\begin{array}{l}1.14(0.40- \\
3.26 ; 0.82)\end{array}$ \\
\hline COPD & $\begin{array}{l}1.00(0.98- \\
1.02 ; 0.92) \\
\end{array}$ & $\begin{array}{l}0.68(0.17-2.76 \\
0.58)\end{array}$ & $\begin{array}{l}0.78(0.14- \\
4.24 ; 0.77) \\
\end{array}$ & $\begin{array}{l}1.00(0.99- \\
1.01 ; 0.64)\end{array}$ & $\begin{array}{l}0.97(0.91- \\
1.03 ; 0.29) \\
\end{array}$ & $\begin{array}{l}1.00(0.96- \\
1.05 ; 0.90) \\
\end{array}$ & $\begin{array}{l}0.96(0.89- \\
1.03 ; 0.25) \\
\end{array}$ & $\begin{array}{l}2.08(0.48- \\
8.94 ; 0.33) \\
\end{array}$ \\
\hline Diabetes & $\begin{array}{l}1.00(0.98- \\
1.02 ; 0.91)\end{array}$ & $\begin{array}{l}1.27(0.55-2.94 ; \\
0.58)\end{array}$ & $\begin{array}{l}2.11(0.95- \\
4.65 ; 0.07)\end{array}$ & $\begin{array}{l}1.00(1.00- \\
1.00 ; 0.49)\end{array}$ & $\begin{array}{l}1.02(0.99- \\
1.05 ; 0.24)\end{array}$ & $\begin{array}{l}1.02(0.99- \\
1.05 ; 0.14)\end{array}$ & $\begin{array}{l}1.01(0.97- \\
1.04 ; 0.68)\end{array}$ & $\begin{array}{l}1.44(0.57- \\
3.64 ; 0.44)\end{array}$ \\
\hline History of kidney failure & $\begin{array}{l}1.00(0.98- \\
1.02 ; 0.92)\end{array}$ & $\begin{array}{l}0.50(0.11-2.29 \\
0.38)\end{array}$ & $\begin{array}{l}0.31(0.04- \\
2.71 ; 0.29)\end{array}$ & $\begin{array}{l}1.00(1.00- \\
1.01 ; 0.18)\end{array}$ & $\begin{array}{l}1.03(0.98- \\
1.08 ; 0.31)\end{array}$ & $\begin{array}{l}1.07(1.02- \\
1.13 ; 0.01)\end{array}$ & $\begin{array}{l}1.02(0.96- \\
1.09 ; 0.47)\end{array}$ & $\begin{array}{l}1.36(0.26- \\
7.19 ; 0.72)\end{array}$ \\
\hline History of cancer (any) & $\begin{array}{l}1.00(0.99- \\
1.01 ; 0.84)\end{array}$ & $\begin{array}{l}2.26(0.93-5.50 \\
0.07)\end{array}$ & $\begin{array}{l}0.83(0.30- \\
2.31 ; 0.72) \\
\end{array}$ & $\begin{array}{l}1.00(1.00- \\
1.01 ; 0.16)\end{array}$ & $\begin{array}{l}1.04(1.01- \\
1.07 ; 0.02)\end{array}$ & $\begin{array}{l}1.03(1.01- \\
1.06 ; 0.02)\end{array}$ & $\begin{array}{l}1.04(1.01- \\
1.08 ; 0.02)\end{array}$ & $\begin{array}{l}0.99(0.35- \\
2.80 ; 0.99)\end{array}$ \\
\hline Psoriasis & $\begin{array}{l}0.96(0.89- \\
1.03 ; 0.28)\end{array}$ & $\begin{array}{l}1.71(0.51-5.78 ; \\
0.39)\end{array}$ & $\begin{array}{l}1.22(0.32- \\
4.61 ; 0.77)\end{array}$ & $\begin{array}{l}1.00(0.99- \\
1.01 ; 0.87)\end{array}$ & $\begin{array}{l}1.01(0.97- \\
1.06 ; 0.59)\end{array}$ & $\begin{array}{l}1.02(0.98- \\
1.05 ; 0.42)\end{array}$ & $\begin{array}{l}1.01(0.96- \\
1.06 ; 0.82)\end{array}$ & $\begin{array}{l}0.22(0.03- \\
1.75 ; 0.15)\end{array}$ \\
\hline $\begin{array}{l}\text { History of Crohn's diseases or } \\
\text { ulcerative colitis }\end{array}$ & $\begin{array}{l}1.26(0.82- \\
1.93 ; 0.28)\end{array}$ & $\begin{array}{l}0.00(0.00-0.00 \\
1.00)\end{array}$ & $\begin{array}{l}0.34(0.01- \\
108.95 ; 0.71)\end{array}$ & $\begin{array}{l}0.99(0.96- \\
1.02 ; 0.35)\end{array}$ & $\begin{array}{l}0.99(0.85- \\
1.15 ; 0.85)\end{array}$ & $\begin{array}{l}1.00(0.89- \\
1.13 ; 0.99)\end{array}$ & $\begin{array}{l}1.01(0.85- \\
1.18 ; 0.95)\end{array}$ & $\begin{array}{l}0.00(0.00- \\
0.00 ; 1.00)\end{array}$ \\
\hline Rheumatoid arthritis & $\begin{array}{l}1.02(0.99- \\
1.04 ; 0.24)\end{array}$ & $\begin{array}{l}0.71(0.21-2.41 \\
0.59)\end{array}$ & $\begin{array}{l}1.01(0.27- \\
3.81 ; 0.99) \\
\end{array}$ & $\begin{array}{l}1.0(0.99-1.01 \\
0.84)\end{array}$ & $\begin{array}{l}0.97(0.92- \\
1.02 ; 0.21)\end{array}$ & $\begin{array}{l}0.97(0.93- \\
1.00 ; 0.07)\end{array}$ & $\begin{array}{l}0.95(0.90- \\
1.01 ; 0.12)\end{array}$ & $\begin{array}{l}0.26(0.03- \\
2.07 ; 0.21)\end{array}$ \\
\hline Polymyalgia rheumatic & $\begin{array}{l}1.00(0.92- \\
1.08 ; 0.94)\end{array}$ & $\begin{array}{l}0.00(0.00-0.00 \\
1.00)\end{array}$ & $\begin{array}{l}0.32(0.01- \\
16.62 ; 0.57)\end{array}$ & $\begin{array}{l}0.99(0.98- \\
1.01 ; 0.36)\end{array}$ & $\begin{array}{l}0.92(0.78- \\
1.09 ; 0.33) \\
\end{array}$ & $\begin{array}{l}1.00(0.91- \\
1.09 ; 0.93)\end{array}$ & $\begin{array}{l}0.92(0.77- \\
1.09 ; 0.32)\end{array}$ & $\begin{array}{l}0.00(0.00- \\
0.00 ; 1.00)\end{array}$ \\
\hline Gout & $1.00(0.98-$ & $0.33(0.08-1.32$ & $2.03(0.62-$ & $1.00(1.00-$ & $1.05(1.00-$ & $1.03(0.99-$ & $1.05(0.99-$ & $0.83(0.17-$ \\
\hline
\end{tabular}




\begin{tabular}{|c|c|c|c|c|c|c|c|c|}
\hline & $1.02 ; 0.95)$ & $0.12)$ & $6.71 ; 0.25)$ & $1.01 ; 0.13)$ & $1.10 ; 0.04)$ & $1.08 ; 0.13)$ & $1.10 ; 0.08)$ & $4.08 ; 0.82)$ \\
\hline Psoriatic arthritis & $\begin{array}{l}1.06(0.84- \\
1.35 ; 0.61)\end{array}$ & $\begin{array}{l}0.00(0.00-0.00 ; \\
1.00)\end{array}$ & $\begin{array}{l}0.00(0.00- \\
0.00 ; 1.00)\end{array}$ & $\begin{array}{l}1.00(0.98- \\
1.02 ; 0.84)\end{array}$ & $\begin{array}{l}1.05(0.91- \\
1.21 ; 0.52)\end{array}$ & $\begin{array}{l}1.00(0.89- \\
1.13 ; 0.97)\end{array}$ & $\begin{array}{l}1.07(0.91- \\
1.25 ; 0.43)\end{array}$ & $\begin{array}{l}0.00(0.00- \\
0.00 ; 1.00)\end{array}$ \\
\hline Ankylosing spondylitis & $\begin{array}{l}0.93(0.81- \\
1.07 ; 0.33)\end{array}$ & $\begin{array}{l}0.70(0.06-7.81 \\
0.77)\end{array}$ & $\begin{array}{l}2.20(0.28- \\
17.52 ; 0.46)\end{array}$ & $\begin{array}{l}1.00(0.98- \\
1.01 ; 0.50)\end{array}$ & $\begin{array}{l}1.03(0.95- \\
1.12 ; 0.46)\end{array}$ & $\begin{array}{l}1.04(0.97- \\
1.12 ; 0.23)\end{array}$ & $\begin{array}{l}1.01(0.92- \\
1.11 ; 0.83)\end{array}$ & $\begin{array}{l}4.81(0.43- \\
54.02 ; 0.20)\end{array}$ \\
\hline $\begin{array}{l}\text { Depression (based on CES-D } \\
\text { thresholds) }\end{array}$ & $\begin{array}{l}0.97(0.94- \\
1.01 ; 0.09)\end{array}$ & $\begin{array}{l}0.62(0.33-1.16 ; \\
0.14)\end{array}$ & $\begin{array}{l}3.10(1.76- \\
5.47 ; 0.00)\end{array}$ & $\begin{array}{l}1.00(1.00- \\
1.00 ; 0.96)\end{array}$ & $\begin{array}{l}1.00(0.97- \\
1.02 ; 0.74)\end{array}$ & $\begin{array}{l}1.01(1.00- \\
1.03 ; 0.33)\end{array}$ & $\begin{array}{l}0.99(0.97- \\
1.02 ; 0.53)\end{array}$ & $\begin{array}{l}1.33(0.71- \\
2.52 ; 0.38)\end{array}$ \\
\hline
\end{tabular}

CES-D - Center for Epidemiologic Studies Depression; COPD - chronic obstructive pulmonary disease; N/E - not estimable; OR - odds ratio; PE - pulmonary embolism;

TIA - transient ischaemic attack 
Supplementary Table 1. Multivariate logistic regression analysis (OR, 95\% confidence interval; p-values for predictors and p-values for non-predictors) for predicting specific morbidities identified as significant on univariate analysis.

\begin{tabular}{|c|c|c|c|c|c|c|c|c|}
\hline & $\begin{array}{l}\text { Mean age at } \\
\text { arthroplasty }\end{array}$ & $\begin{array}{l}\text { Gender (males: } \\
\text { females) }\end{array}$ & Ethnic origin & $\begin{array}{l}\text { Mean height at } \\
\text { aged } 25\end{array}$ & $\begin{array}{l}\text { Mean weight at } \\
\text { aged } 25\end{array}$ & $\begin{array}{l}\text { Maximum } \\
\text { adult weight }\end{array}$ & $\begin{array}{l}\text { Minimum } \\
\text { adult weight }\end{array}$ & $\begin{array}{l}\text { Type of } \\
\text { Arthroplasty }\end{array}$ \\
\hline History of heart failure & $\mathrm{N} / \mathrm{E}$ & $\begin{array}{l}\text { OR: 0.21 (0.94- } \\
23.95 ; 0.06)\end{array}$ & $\mathrm{N} / \mathrm{E}$ & 0.55 & $\mathrm{~N} / \mathrm{E}$ & 0.29 & $\mathrm{~N} / \mathrm{E}$ & $\mathrm{N} / \mathrm{E}$ \\
\hline History of cancer (any) & $\mathrm{N} / \mathrm{E}$ & $\mathrm{N} / \mathrm{E}$ & $\mathrm{N} / \mathrm{E}$ & $\mathrm{N} / \mathrm{E}$ & 0.16 & 0.08 & 0.11 & $\mathrm{~N} / \mathrm{E}$ \\
\hline Gout & $\mathrm{N} / \mathrm{E}$ & $\mathrm{N} / \mathrm{E}$ & $\mathrm{N} / \mathrm{E}$ & $\mathrm{N} / \mathrm{E}$ & $\begin{array}{l}\text { 1.05 (1.00-1.10; } \\
0.04)\end{array}$ & $\mathrm{N} / \mathrm{E}$ & 0.99 & $\mathrm{~N} / \mathrm{E}$ \\
\hline $\begin{array}{l}\text { Depression (based on CES-D } \\
\text { thresholds) }\end{array}$ & $\mathrm{P}=0.51$ & $\mathrm{~N} / \mathrm{E}$ & $\begin{array}{l}\text { OR: } 3.578(1.92- \\
6.66 ;<0.01)\end{array}$ & $\mathrm{N} / \mathrm{E}$ & $\mathrm{N} / \mathrm{E}$ & $\mathrm{N} / \mathrm{E}$ & $\mathrm{N} / \mathrm{E}$ & $\mathrm{N} / \mathrm{E}$ \\
\hline
\end{tabular}

CES-D - Center for Epidemiologic Studies Depression; COPD - chronic obstructive pulmonary disease; N/E - not estimable; OR - odds ratio; TIA - transient ischaemic

attack 